In the Philosophical Magazine for November 1884, and for February 1886, I have shown that the numerical value $y$ of the symbol of an element within the common system is given with great accuracy by the equation

$$
y=15 p-15(\cdot 9375)^{t}
$$

where $p$ is the number of the period, and $t$ is a whole number, easily approximated to, on the scale of celestial temperature. Our ordinary elements-that is to say, all that are known to us with the exception of hydrogen-are thus seen to correspond to what might be expected from a law of polymerisation affected by the inverse of Dulong and Petit's law of cooling. They appear to be comprised within sixteen periods only.

These considerations lead to the inference that a variable-star is one that is engaged in making "elements." All stars, therefore, either are, or must at one time have been, variable-stars.

Glasgow, March I EDMUND J. Mills

\section{Do Young Snakes take Refuge in the Stomach of the Mother?}

The letters of Messrs. Middleton and Creole (NATuRE, vol. xxxiii. pp. 176 and 269 ) in relation to the above-indicated reputed habit of serpents, directed my attention to some considerations and facts bearing upon the question at issue.

It has long been a popular belief-in relation to the European viper, as well as the American rattlesnake-that when the female is suddenly surprised she opens her mouth and permits her young to run dozen her throat. Some of the English viper-catchers deny that any such thing ever happens; and for a long time I was disposed to ascribe the origin of the popular opinion to the fact that, these serpents being ovo-viviparous, they are sometimes found with the young in the oviduct; which might lead persons to suppose that they were in the stomach. But the following account, given by the well-known French naturalist and traveller, M. Palisot de Beauvois, is so direct and positive, that my faith in the above explanation has been seriously shaken.

He asserts "that he saw a large rattlesnake, which he happened to dis'urb in his walks, coil itself up, open its jaws, and instantly receive five small ones which were lying by it and instinctively rushed into its mouth. M. de Beauvois retired and watched the snake, and, about a quarter of an hour after, he saw her discharge them. He approached a second time, when the young retired into its mouth with greater celerity than before, and the snake immediately moved off among the grass and escaped" (vide Rees' "Cyclopædia," vol. x., Article "Crotalus," cited from the Transactions of the American Philosophical Society). Testimony so clear and distinct from a scientific man is hardly to be gainsaid.

Berkeley, California, February i7

\section{The Coal-Dust Question}

Sik Frederick Abel ha: not fortified his statement by even one quotation from the writings of one of those workers "antecedent to and contemporaneous with" myself, who, according to his letter in the last number of NATURE (p. 4I7), have taken the variable specific heat of air into account in drawing com parisons between experimental effects obtained in practically open apparatuses and the corresponding effects to be expected in a great explosion taking place in the practically closed space represented by the workings of a mine.

Secondly, I am entirely at a loss to know what are the "very obvious facts" which forbid the conclusion at which $I$ have arrived, namely, that coal-dust plays the principal part in most great explosions in mines. They have not yet been pointed out by any author so far as I have been able to learn.

Lastly, Sir Frederick's statements, to which I called attention in my letter in NATURE of December 31 (p. 197), were made for the most part before popular audiences, very few of whom will probably take the trouble to wade through the Report of the Royal Commission on Accidents in Mines in order to verify his concluding remarks for themselves. W. GALLOWAY

\section{Permanent Magnetic Polarity of Quartz}

To my letter in NATURE for February 25 (p. 391) you have added an editorial note, quoting a passage from Tumlirz's paper which has no bearing on any of the points at issue.
In your original note you stated that Tumlirz has discovered a permanent diamagnetic polarity of quartz. To this I objected, saying that the permanent polarity was paramagnetic, not diamagnetic, and you reply by a quotation stating that quartz is a diamagnetic body showing permanent polarity, a very different statement indeed from your original one.

A permanent diamagnetic polarity could only mean that quartz placed between the poles of a magnet should show permanent north polarity at the end placed opposite the North Pole. Tumlirz is perfectly distinct and explicit that this is not the case, but that the permanent polarity acquired is in the same direction as it is in iron. There is no room for two opinions as to the meaning of 'Tumlirz's words.

ARTHUR SCHUSTER

[Our correspondent who furnished us with the original note informs us that Prof. Schuster was entirely right in the definition of the term diamagnetic polarity, and that his informant in Vienna had been misled in using the phrase permanent diamagnetic polarity for permanent polarity of a diamagnetic body. The sentence which we quoted from Dr. Tumlirz's now-published paper we quoted because it is the one in which he points out the essential novelty of his discovery, which we and our correspondent regarded, and still regard, as one of very great import ance. Our thanks are due to Prof. Schuster for pointing out the ambiguity. -ED.]

\section{The "Muir Glacier" of Alaska}

IN Mr. G. W. Lamplugh's interesting article on "The 'Muir Glacier' of A laska," published in your issue for January 28 (p. 299), appears the erroneous statement that Glacier Bay opens into Chilcoot Inlet. Chilcoot Inlet is at the head of Lynn Canal, the approximate latitude and longitude being $59^{\circ} 20^{\prime} \mathrm{N}$., and $135^{\circ} 20^{\prime}$ W. Glacier Bay opens into Cross Sound (or Icy Strait) about latitude $58^{\circ} 3 \mathrm{O}^{\prime} \mathrm{N}$., and longitude $135^{\circ} 5 \mathrm{O}^{\prime} \mathrm{W}$. Lynn Canal is an extension of Chatham Straits, both running nearly north and south. Cross Sound connects the latter with the Pacific Ocean, and runs nearly east and west, entering Chatham Straits south of the southern limits of Ljnn Canal.

Washington, February 25 Chauncey Thomas

\section{THE SURVEY OF INDIA ${ }^{1}$}

I $\mathrm{T}$ has been well said that "l'exacte connaissance topographique qui est un facteur de l'avancement des sciences et de leurs applications pratiques, est aussi un élément constitutif du progrès national." ${ }^{2}$ India is a country which, ever since the establishment of British dominion in the east, has been prolific of surveys of very various degrees of exactitude, ascending from the rough and rude reconnaissances which were needed for the speedy acquisition of some knowledge of the general geography, to, first, a fairly close representation of all topographical features, and, finally, to an exact delineation of the boundaries of all properties-of private individuals as well as of the State-in the richer and more densely populated portions of the British districts. Commencing at the coast lines, with the primary object of furnishing charts for the guidance of navigators, with a view to the rapidly-increasing traffic between India and Europe, they were extended inland, here and there, as different parts of the country became subject to British influence. Astronomical determinations of the latitude and longitude were employed in the first instance as a general basis for the geography, but not proving satisfactory, they were abandoned at the commencement of the present century, when the Great Trigonometrical Survey was originated, which has been of such value for geodesy, as well as geography. The survey work may be broadly classified as non graphical and graphical, the former trigonometrical and geodetic, the latter delineative of the configuration of the ground and of whatever has been raised on its surface. I "General Report on the Operations of the Survey of India Department,
administered under the Government of India during I883-84." Prepared under the direction of Col. G. C. De Pree, S.C., Surveyor-General of India. " "Importance de la Cartographie officielle." C. D. Carusso. Genève, ז836́. 